\title{
COVID-19 in India, Perspectives from Inside a Resurgent Pandemic
}

Japmeet Sandhu,OMS III, VJS Virdi, MD

"After this lockdown after March, I have segregated myself and opened up my own health care facility, which is by the name of Nimbus Hospital. This hospital has ten beds dedicated to pediatrics and neonatology. Plus, we are doing pediatric surgery also because my partner is a pediatric surgeon, so we have a facility of doing pediatrics and neonatal medicine and surgical practice under one roof."

What is your practice, how long have you been practicing?

I'm Dr. Virdi. I've done my education in pediatrics and fellowship in neonatology. I have been practicing since 1998, almost 20 to 25 years of practice. Most of my practice has been in the private sector, and I practice neonatology as well as general pediatrics.

Tell me about your hospital. How many beds? Whom do you treat? How many patients do you see?

Prior to the lock down last March, I was engaged with a bigger hospital, which was a 50 bedded hospital multi-specialty where I was looking after the pediatrics and neonatology department itself. It was a level 2 NICU plus a level 1 to level 2 pediatric. We used to ventilate neonates plus taking care of preterm and term babies. In pediatrics, we were not ventilating but taking care of general pediatrics.

After this lock down after March, I have segregated myself and opened up my own health care facility, which is by the name of Nimbus Hospital. This hospital has ten beds dedicated to pediatrics and neonatology. Plus, we are doing pediatric surgery because my partner is a pediatric surgeon, so we have a facility of pediatrics and neonatal medicine and surgical practice under one roof. That is the setup I'm now working.

What encouraged you to branch out and start your own hospital? Was it due to COVID?

Yes, multiple issues, one that we were not able to practice social distancing and segregate our patients because there was a lot of adult patient population, also in that multi-specialty hospital. So we had to come over to a separate place where we could, practice social distancing as well as practice exclusively pediatrics, for that

Japmeet Sandhu, OMSIII interviews VJS Virdi, MD of Nimbus Hospital in Mohali, India. matter, so we segregated ourselves and started up this facility.

What is your patient population like? Where is the hospital located? (rural, urban, North, South etc.)

It is located in Mohali, which is a satellite town of Chandigarh in Punjab. It's an urban area, in a sector that is still not completely built, it's an upcoming sector. It is not as good as the previous hospital which was located in the other sector. But definitely, it is in an urban area, and we are catering to some local population, but most of the population we are catering to is from around the area, like 40 kilometers. They do come from the rural background, also because most of my patients are those who have been attached with me for the last 20 to 25 years.

\section{The first year of COVID did not hit India as hard}

Why do you think India initially did not have many problems/ was able to manage COVID better?

I think it was managed at an acceptably good level initially because the government was very prompt in taking up the lock downs as well as arranging the facilities. Big infrastructure was built up within days or months for the first wave of COVID, but then the things were dismantled very quickly thereafter once they found that the things are going away, it is fading away, and they did not prepare themselves for the second wave, so this second wave has hit very hard for the Indian population.

In the initial wave, probably the population, was also geared up and convinced to practice social distancing and other majors like putting up a mask and other things. But as time went by, they became complacent, and people started lowering their guard, so that is why the things have been very hard for the last one and a half months now.

How was the initial year for you?

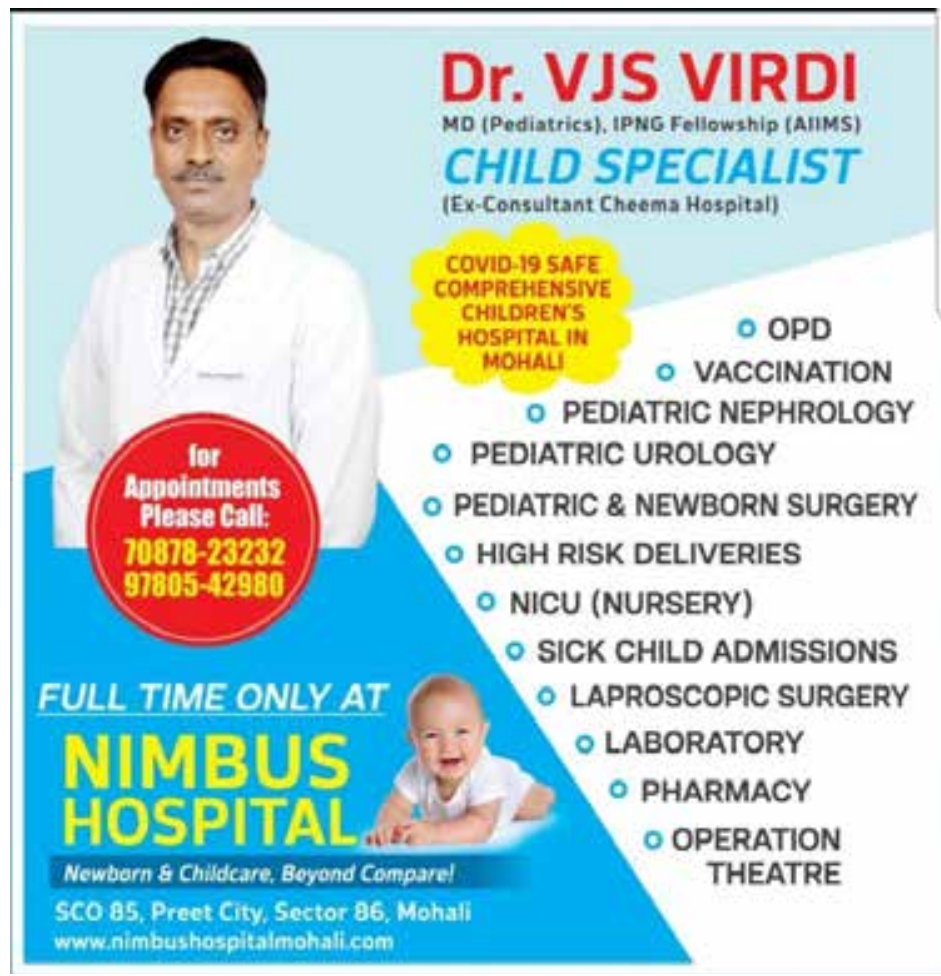




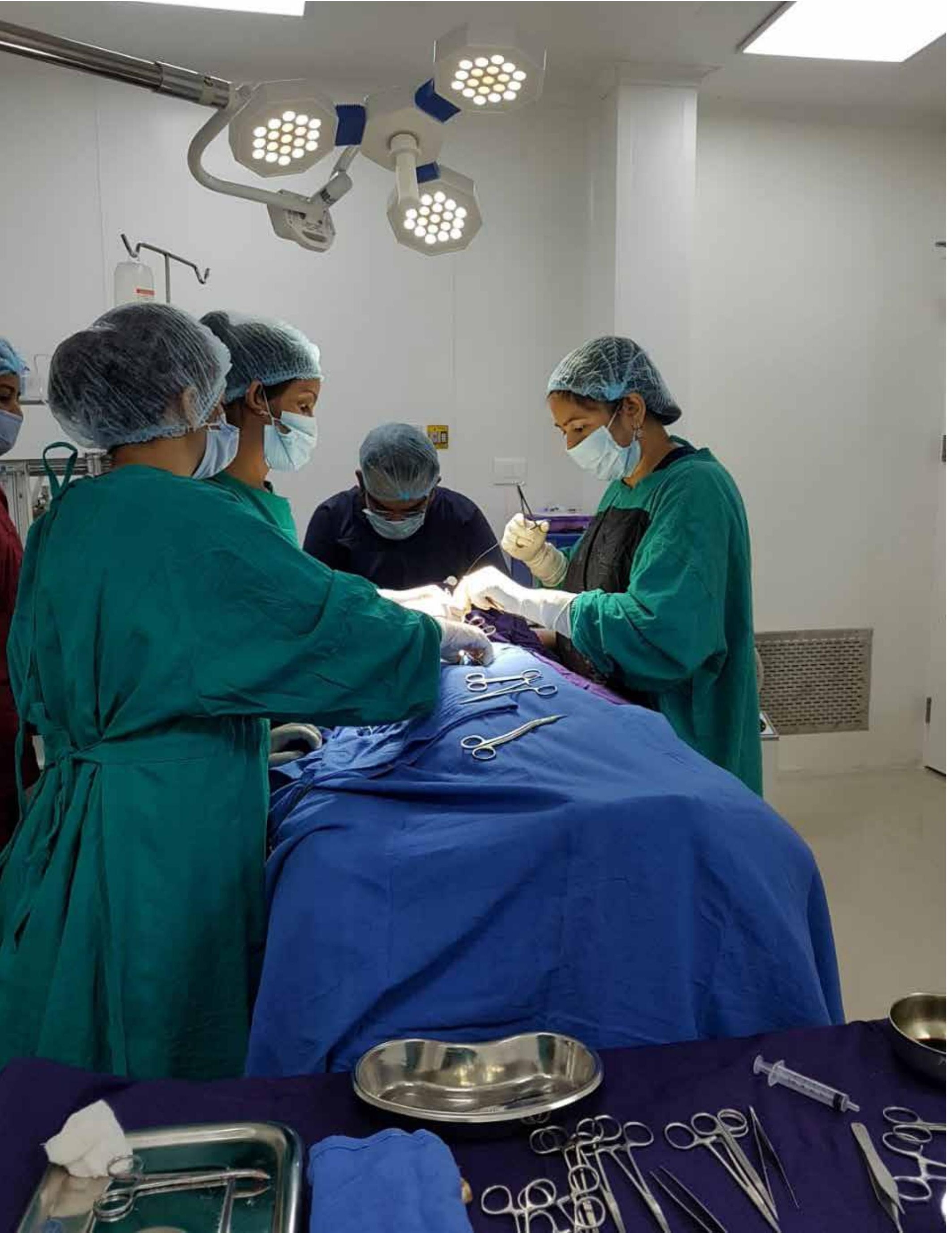


Was your experience typical of other areas in India, or did you have any specific problems pertaining to your demographics?

One thing is that actually the pediatric population or the neonatal population was not that severely affected in the first wave. We did not see very many; I would definitely agree that I didn't even see a single COVID pediatric patient in the first phase.

But now we have seen neonates as well as the general pediatric population suffering or having COVID positive reports, but we are not taking care of those who are going to level three facility to require that medical health.

I have seen it in neonates last week. I had a neonate around 28 days old whose mother tested positive, and then the child also tested positive, but then that did not have any complications and has recovered. They have a better response to the given infection. They are not getting to so many complications as the adults.

In this second wave, young adults or maybe middle-aged adults like 30-35 years are getting a lot more complications when compared to the first wave, where the elderly were more affected.

\section{"And now, a very large percentage of population have to go out, they have to earn for their family, for themselves, and that is what is taking them away or lowering their guard."}

\section{So this second wave is affecting young adults a lot more?}

Yes, and this is probably because of the mutant B117

Was COVID a problem in certain parts of India, and it was just under reported in the news?

\section{Why do you think there is a surge in COVID now?}

Multiple reasons. One that the people have lowered their guard. Two, the administrative workup has also lowered their guard. Three, it could be the mutant which has caused this much havoc and, fourthly, you know people have become fed up now, with the repeated lock downs and not earning as much because India has such a vast population. And now, a very large percentage of population have to go out, they have to earn for their family, for themselves, and that is what is taking them away or lowering their guard.

\section{Is there a lot of government support?}

No, there is not a lot of governments support either economic or for that matter, you know I might not be the right person to be saying this, but they have not actually come up to the mark, to provide even the healthcare facilities. Now this COVID spread is going towards the villages, it is going towards the countryside.

So in the previous wave, there were very few reports of people being affected in the countryside or in the villages. And at that point of time in the previous wave, people in the villages themselves took up their cause and did not allow the city people or outsiders to enter their villages. But now that guard has also gone, so now COVID has entered into the interiors, especially in Punjab, Uttar Pradesh-I think in every place in India it has gone into the interiors now, and that is why it affects a very large base of population.

Are a lot of these villages pretty far from hospitals?
Yes, definitely. People will have to travel at least 40 kilometers to reach a level three hospital in case they require that stay.

What are you seeing now?

If your hospital/ area is doing ok, can you describe how other areas are doing?

Do you have oxygen, ventilators, and medications?

Are you running out of hospital beds?

How are you treating?

The government guidelines or the WHO guidelines combined are being followed for all COVID patients. Initially, they were quarantining every person who tested positive; then, they started coming up with the idea of home quarantining. And now, most of the asymptomatic or mildly symptomatic patient, they are managed at the home level with teleconsultation by the government sector doctors, doctors engaged by NGOs or the private doctors who give teleconsultation on a fee basis. But those requiring oxygen support or ventilator support, they have to be taken to the government or private sector where the facilities for level 2 or level 3 are available. And then, they are managed according to the protocols that the institutes follow.

\section{Is it common to run out of supplies or have to share hospital} beds?

Yes. Many have been seen even sitting outside the emergencies with their own oxygen cylinders and taking oxygen on their own. People even started providing free oxygen cylinders outside the religious places like Gurdwaras, especially in Delhi and Uttar Pradesh. And people have been hoarding also, I would say oxygen cylinders and oxygen at their homes, also for home oxygen therapy. Maybe after they get disturbed or maybe in the initial phase of the illness, where they feel that they will not be able to get a bed in the hospital and they have to fight for this.

With all of that shortage, how is your pediatric hospital doing?

We ran out of oxygen. We even had to deny admission to nonCOVID patients. Just last week, we had a child with Meckel's Diverticulum who had an acute intestinal obstruction and required surgery immediately. But we had to shift that patient to a tertiary level hospital where our pediatric surgeon went and operated on the child.

So definitely, things have not been good for the small care centers. The government is not allowing the COVID centers to be in less than 50 bedded hospitals. The supply chain to these hospitals, like my hospitals, is very less. It has to be arranged on your own, and then, if you are not able to arrange one day, it falls on the hospital owner or the doctor who is treating and that is what causes the medical, legal complications, and that is why we are at this point of time, not able to help very many patients, even the non-COVID patients who require pediatric admissions or neonatal admissions.

And oxygen has all been rationed. The oxygen is now under the control of the administration. They are keeping a daily check on every cylinder which is being taken out from the facility, where the oxygen is being bottled or manufactured, so that is how they're doing it, and they're taking it away on their own. Some of the time, even the bigger containers of oxygen are being buried under police protection.

\section{Is your hospital seeing COVID patients?}

We are not allowed to admit COIVD patients. We cannot do that. We are just providing them the home teleconsultation for asymptomatic of mildly symptomatic patients. If we feel on the telecon- 
sultation that they require hospitalization or oxygen, we refer them to a COVID center, be it private or public sector. Less than 50-bed hospitals are not allowed to admit COVID patients.

Is the hospital you worked at before allowed to admit COVID patients?

It was a 50-bed hospital, but I have feedback, and they are still not admitting COVID patients. You have to get all these statuary permissions to run a COVID hospital.

Because of these shortages and limitations, are you finding it is harder to care for non-COVID patients?

Yes, definitely, there is a lot of pressure. We are not able to help them out. We are not able to do as much work as we could with the given resources. This is only because there are two issues. One, the issues of logistics or the oxygen which is being rationed which is not being allowed to the smaller hospitals or Non COVID hospitals or non-priority areas. And secondly, people also are now very afraid to get admitted to a hospital because of the dangers of cross-infection or other things, so to a limit, they try to avoid getting admitted for even the acute emergencies. Those are issues affecting us, but definitely, we are helping our patients on the telephone consultations, video consultations, as well as in-person consultations for situations where we feel that we have to call the patient and examine physically.

\section{Are there any PPE shortages?}

We are having enough supplies. There was a shortage of N95 masks for medical personnel who are working in the ICU but then it is a place-to-place problem. Like every place has its own problems, and definitely, masks tend to go into short supply for many of the places. But AAA marks for the general population or for us who are not seeing COVID patients that is in abundance.

India currently has three vaccines available (Sputnik V, Covishield, Covaxin) but why is there a problem with logistics?

\section{Why are there vaccine shortages?}

\section{Why is it so hard to vaccinate people?}

Three vaccines are available. I got my own vaccine on a priority basis because of being a health care professional. My second dose was two months back.

\section{Are most healthcare workers vaccinated?}

No, for the initial dose, there was a lot of hesitation even amongst the healthcare personnel to receive the vaccination. It was Covishield only, which was available at that time. What I have read is that almost $40 \%$ of healthcare personnel they had refused a dose at that point of time. Some departments in big hospitals have succumbed to COVID-related illness because they did not get their vaccinations in time. There was initial resistance, but now that things have picked up, the general population is also not very reluctant. They are very keen to get the vaccination, but now the vaccine is in very short supply these days. Especially after May 1, it has been in very short supply.

Other than India having a very large population, why do you think the vaccine is in short supply?

One reason was the population. Second reason was that India exported the vaccine to other countries while it was still required in our own country. Third reason is that it is a centralized process by the central government to procure the vaccine and then distribute it to the states. The federal structure was not followed in spirit. And then after May 1, they have allowed the states to procure their own vaccines directly from the company. There are different rates for the central government, which is the minimum. A different rate for the state government which is in the middle and a very different rate for the private practitioners or the private players which is on the very high side.

Most of the Indian health care relies on private health care system. Almost $70 \%$ rely on the small healthcare facilities or the private healthcare facilities. The corporate teams are able to procure the vaccines directly from the company. But these small players will not be able to get the vaccine at their own level and offer it to the general population in their local area, so that is another constraint.

Why does most of India's population rely on these private hospitals? Is it hard to go to a government or corporate one?

Before this COVID struck, the government infrastructure, especially for Level two, Level three care was not up to date. You have a shortage of everything in the government hospitals. It is not at all the kind of social security that we get in the developed countries. You have to be on your own whichever way you go, either in the private or public sector. After the COVID struck, the government took up very many reforms, very many challenges were taken up. Then it was made mandatory that people will be put into quarantine only in government facilities. So people had to definitely go towards the public sector setup. It was revamped also, but then things slackened after the first wave, and that is why it has shown up like this in the second wave.

How do you give and store vaccines when it comes to those who don't live in cities

\section{How does it get to those in villages or even slums?}

See, India has done a remarkable job in containing vaccinepreventable diseases. For example, we are Polio-free. We were able to take these vaccines to the doorstep level of even the rural population or the remote population. That is not a problem. The vaccines, which are to be stored at two to eight degrees, can always be taken up and shifted to the doorstep, at the very remotest places, but the thing is, the vaccine itself is still not available for that but. Otherwise, everybody would have done their bit to vaccinate the whole population in there, given it.

So you are capable of vaccinating the population. It's just a matter of vaccine number?

Yes, definitely we had every system in place to do that, but the thing is, the government first opened the vaccination for those who were above 60 . Then selectively about 45 with co-morbidities and now after first May they have opened for 18 to 45 years and for those less than 18 years, they're still not allowing vaccination.

So if someone over 18 years was to get the vaccine in India today, is there a long waitlist?

Yes, yes, it is a very long way. They have to get registered on a particular app. They have to wait for their appointment, and even on the given appointment date, they may not get their vaccine because the vaccine might not be available on that particular day. It was very easy to get vaccines when it was for the selective group, like the health care workers or the frontline warriors but, as the things opened up, the system started crumbling down, and now it is just you know, a rat race to get the vaccine, but not everybody is able to get the vaccine.

Since this, have you noticed a lot of the general populating taking COVID even more seriously, such as more people are wearing masks and social distancing?

See, there is still a lot of complacency in the general population. They are still not up to the required level of guard which is required regarding masking or social distancing. I suppose they are more worried or more concerned about earning their livelihood, and that is why they do not want to get locked down or do something. But I personally believe, even if there is no lock down, even if they 
are going to their workplace, they should be taking up the general precautions like masking and social distancing in a good way. It is not being practiced religiously. That is one thing I would say. There have been social gatherings. There have been religious gatherings. And all these things in the last one and a half months have led to a very widespread disease in the urban as well as rural population.

\section{"A lot of things need to be done. I} believe one that the vaccine supplies should come up very quickly. The other players in the field should also be given express entry for the vaccine production as well as delivery for the Indian population because we have a huge population. To cover that population, to go anywhere near the herd immunity, we need to vaccinate a very large number of people."

How does the government play in this? Are they mandating a lock down or encouraging these gatherings?

See, they've given these powers to the district magistrates or the distract electors. So they are the ones who are taking up this on a day to day basis, depending on the infectivity rate, the number of active cases in the area and the number of deaths which are occurring, and then they are advocating or putting up the lock downs for a brief period. Our neighboring state Haryana has been under lock down for the last 15 days now. Similarly, Delhi has been under lock down after third May till now. It is in a segregated basis. The places where there is a very high case load, they are certainly opting for lock downs. There are containment zones also where there is a very high proliferation of the disease. They are doing micro containment for those areas. These things have to be managed on a district level by the district electoral or the district minister.

\section{Comment on your feelings}

What do you think needs to be done to find a solution?

Do you think you will need additional vaccines from elsewhere?

A lot of things need to be done. I believe one that the vaccine supplies should come up very quickly. The other players in the field should also be given express entry for the vaccine production as well as delivery for the Indian population because we have a huge population. To cover that population, to go anywhere near the herd immunity, we need to vaccinate a very large number of people. So we need to have more players because one or two companies will not be able to ramp up their production overnight and provide vaccination to all those who require. That is one thing. Secondly, more awareness is required amongst the general populations for them to opt for vaccination as a way to prevent a severe disease. Because there are a lot of rumors in the air, on the social media that even after getting two doses of vaccine, people are getting positive or people are dying, but this at present time is misinformation for these general population.
The vaccine is for their own good, and they should opt for getting vaccinated. Also the infrastructure for vaccinating a large group of populations should also be ramped up. It should be done on a shift basis rather than doing it for a few hours in a day so that you are able to cover up a large number of population, but this is only possible if you have an adequate supply of the vaccine.

Like you mentioned with the media, have you found that Indian media is down playing this COVID situation or are they giving accurate information to the public?

No, I don't believe the media is doing justice to themselves as well as the general population. Lately, the things have started changing, but if you go by the general media, things were not very good at some point of time, like 1-1 1/2 month back. But lately, things have started opening up. They have started reporting the realities which are there, but they need to do a lot of groundwork, a lot of research in their local area, local population, and local facilities. Then they will be able to project a picture of what is there and what is required that comes into the notice of the local government.

\section{How can we help?}

What is it that you need, and if you feel that you don't need anything, what do people in India need to turn things around? If anyone has personal shortages, how can we help? What can countries such as the US who has resources, do?

Definitely, these days I think oxygen containers are in session or in demand, whatever the way you put it. But definitely oxygen equipment, for that matter: like the oxygen regulators, the oxygen cylinders, and the oxygen concentrators. These are all things in short supply. The black markets are having a heyday in this. They are actually selling these at exorbitant prices, and for that matter, even the drugs, whether they have been useful for the disease or not, like remdesivir or tocilizumab, which is still not being produced in India. But we are definitely short on these drugs. So this is not my personal experience, this is what I gather from the media or the groups that we are involved in, but definitely, there is a shortage of drugs and shortage of oxygen equipment. For that matter, ramping up the infrastructure also is important, such as bed facility, building new infrastructure for at least level 2 facilities where people can get oxygen on a bed under medical supervision. Not on a home care basis or their own setup. They should not be doing that. They should also not be seen sitting outside the emergencies of hospitals and taking up oxygen from their own cylinders. That infrastructure has to be ramped up. The government is now again ramping up the infrastructure, but they're very quick to dismantle everything. They had built up 500 bed, 1000 bed facilities in the initial wave, but they dismantled it very quickly. And now they are doing it again. There are many NGOs and religious groups which are coming forwards. I know in Punjab, they are coming up with 500 bed or 200 bed facilities at very many places, now with facilities for oxygen, with the help of either cylinders or oxygen concentrators. So those are the things which would be required in the coming days.

\section{Where are the NGOs or religious groups getting supplied?}

These religious groups, like the Delhi Gurdwara Management Committee, they have their own resources because they have been doing very well over these theirs. And the NGOs, like the Khalsa Aid, they have resources from or funding from other countries like UK, your country, Canada, or other places. These are the players that are doing this.

So if someone were to donate, it would be good to donate to these players?

Definitely, I think that will be the best way. Your donation will not reach the masses directly from your end so it has to be through somewhere. Media and these big players have to be worked in to 
provide these facilities for the common population.

Disclosures: The authors note no disclosures

NT

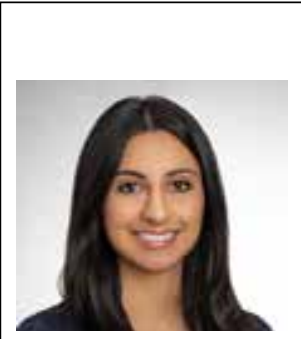

Japmeet Sandhu, OMS III

Western University of Health Sciences

Pomona, CA

Email: japmeet.sandhu@westernu.edu

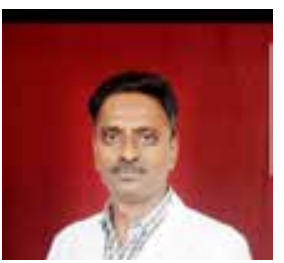

VJS Virdi, MD

Department of Pediatrics

Department of Neonatology

Nimbus Hospital

SCO-85, Sector-86

Preet City, Mohali, India

Email: nimbushospital2020@gmail.com

Telephone: +91- 7087823232, 9780542980

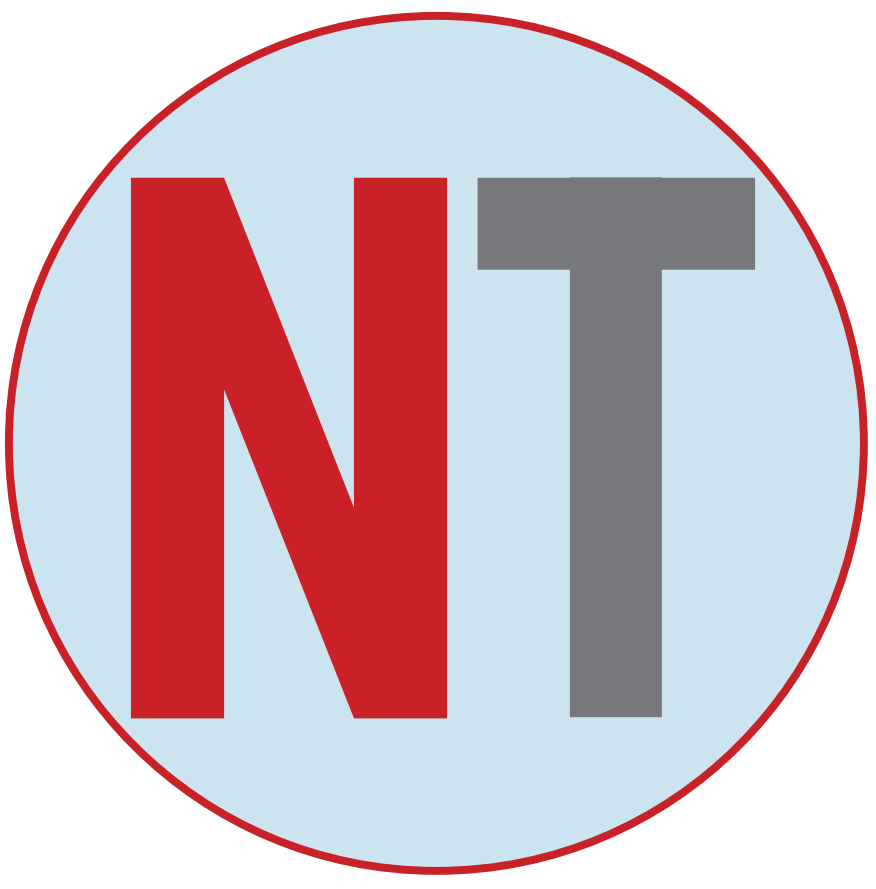

TAKE THE NECESSARY STEPS TO

\section{ELIMINATE INEQUITIES}

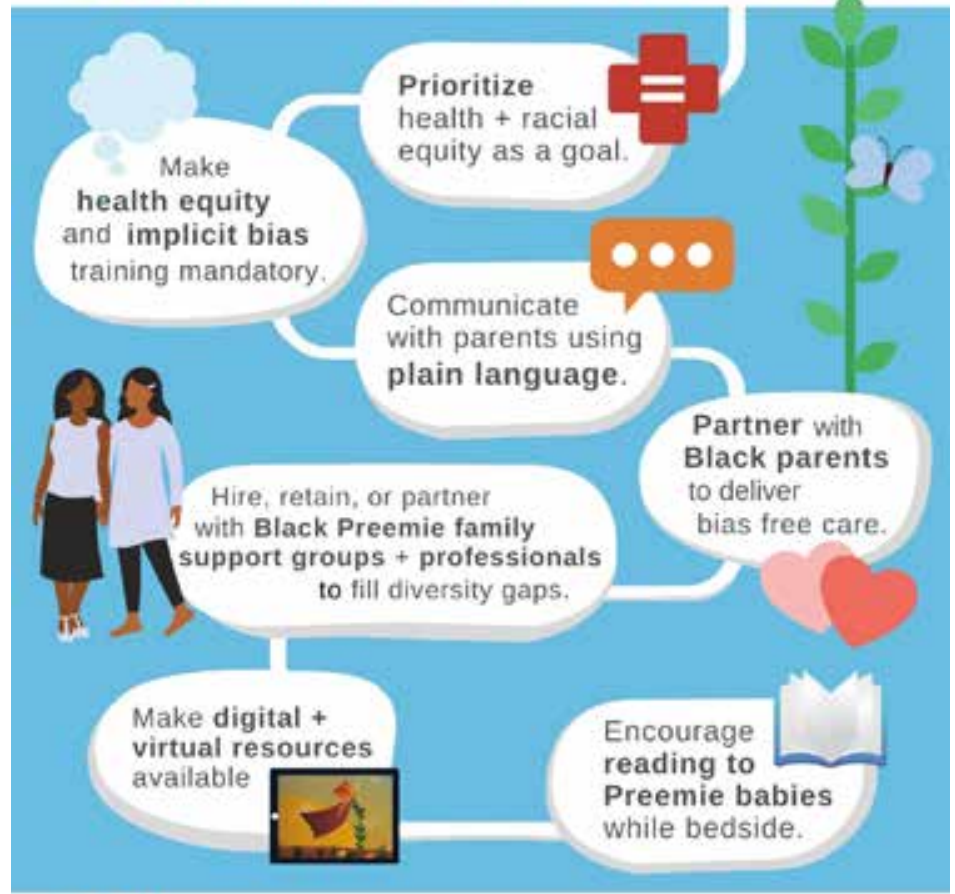

QU AP

ONCEUPONAPREEMIEACADEMY.COM O2020 BY ONCE UPON A PREEMIE ACADEMY

\section{New subscribers are always welcome! NEONATOLOGY IQDAY}

To sign up for free monthly subscription, just click on this box to go directly to our subscription page

\section{Readers can also follow NEONATOLOGY}

via our Twitter Feed @NEO 